\title{
Reproductive Development, Seed Yield and Seed Quality of Gloxinia (Sinningia speciosa) in a Closed Plant Production System as Influenced by LED Light Quality and Intensity
}

\author{
Sunisa Sudthai and Siriwat Sakhonwasee* \\ Program in Horticulture, Faculty of Agricultural Production, Maejo University, Chiang Mai 50290, Thailand
}

\begin{abstract}
The flower seed industry is facing a variety of issues related to ongoing climate change. The closed plant production system (CPPS) may be a solution to these issues as the environment inside the system can be fully controlled to allow seed production from many plant species. In this study, the influence of an artificial light condition, one of the key factors influencing plant growth and development in CPPS, on gloxinia (Sinningia speciosa) seed production was investigated. Three types of lights: warm white $(3200 \mathrm{~K})$, daylight $(6500 \mathrm{~K})$, and red and blue lights (RB) at a photosynthetic photon flux density of either $150 \mathrm{or} 200 \mu \mathrm{mol} \cdot \mathrm{m}^{-2} \cdot \mathrm{s}^{-1}$ were applied to gloxinia plants. The highest vegetative growth was found in plants grown under $3200 \mathrm{~K}$ at $200 \mu \mathrm{mol} \cdot \mathrm{m}^{-2} \cdot \mathrm{s}^{-1}$ light but this did not correlate with seed yield. Plants grown under RB light exhibited the most compact canopy. Day to anthesis, flower diameter and percentage of pod set were not significantly different among the light treatments. Gloxinia plants grown under RB light at $150 \mu \mathrm{mol} \cdot \mathrm{m}^{-2} \cdot \mathrm{s}^{-1}$ had the highest seed yield, which is attributed to higher pollen elongation and flower number. The effect of light quality on seed yield is strongly dependent on light intensity. Moreover, treatment with RB light resulted in longer pollen grains and seeds than the other light quality treatments. Gloxinia seeds from all light treatment exhibited more than $80 \%$ germination and similar seed vigor. The results from this study suggest that CPPS, with suitable light conditions, may be used for commercial gloxinia seed production.
\end{abstract}

Key Words: artificial light, closed plant production system, pollen development, seed production.

\section{Introduction}

Seed is a high value agricultural commodity. In 2018, the global seed market was 42 billion USD and is projected to grow substantially (FAO, 2018; IHS Markit Agribusiness Consulting, 2019). The flower seed market, unlike other seed markets, is characterized by the demand for a wide range of species and very high seed quality (McDonald and Kwong, 2005). Flower seed companies are therefore faced with complications as high-quality seed production of individual species requires different environmental conditions. This is exacerbated by an ongoing climate change phenomenon which is causing unexpectedly high temperatures and water shortage events resulting in a reduction in seed

Received; June 24, 2021. Accepted; September 13, 2021.

First Published Online in J-STAGE on November 30, 2021.

Special Issue "Plant factory and modern greenhouse".

No conflicts of interest declared.

* Corresponding author (E-mail: siriwat@mju.ac.th). yield (Hampton et al., 2016). It was suggested that current seed production sites may need to be moved to avoid the negative impact of climate change on seed yield and quality (Hampton et al., 2013), however, this is not an option for many seed companies. The closed plant production system (CPPS) may be a solution to these issues since the climate inside the system can be fully controlled to match the requirement of an individual plant species for seed production and the system can be established almost anywhere.

The idea of using CPPS for seed production was mentioned previously (Kozai and Niu, 2016; Niam et al., 2019) but, to our knowledge, there are no published research articles directly focused on this topic. However, numerous researchers have explored the effect of environmental factors inside CPPS on plant reproductive growth, which can be linked to seed production. In particular, light conditions are known to be one of the major factors influencing plant growth patterns and it was shown that manipulation of light conditions may affect the reproductive development of 
various plant species inside CPPS (Park et al., 2016; Jähne et al., 2020). For example, a study examining development of Petunia plants under white, monochromatic red and blue lights showed that blue light from light-emitting diode (LED) reduced the number of days to flowering when compared to white light. In the case of red light, the flowering promotion effect occurred only in plants grown under a photosynthetic photon flux density (PPFD) of $150 \mu \mathrm{mol} \cdot \mathrm{m}^{-2} \cdot \mathrm{s}^{-1}$, whereas those grown under $70 \mu \mathrm{mol} \cdot \mathrm{m}^{-2} \cdot \mathrm{s}^{-1}$ did not flower. In addition, both monochromatic light treatments resulted in a significantly lower number of floral buds per plant (Fukuda et al., 2016). It was also found that Cyclamen plants grown under monochromatic red or blue lights exhibit a lower flower bud number than those grown under fluorescent white light and combined red and blue light (Heo et al., 2003). Thus, results from the studies in Petunia and Cyclamen show that light quality may have a significant effect on plant reproductive development, and monochromatic light reduces the number of flowers, which may not be suitable for seed production in CPPS.

Apart from flowering, pollen development has also been studied under different artificial light conditions. High light intensity was shown to increase the percentage of maize pollen tubes that reach the micropyle of wheat ovules; this effect depends on the maize cultivar (Campbell et al., 2001). In peanut, it was found that red light promotes pollen tube elongation (Chhabra and Malik, 1978). Another study, in Cyrtanthus mackenii, tested the effect of LED light quality, namely, violet, blue, orange, red and far-red lights, on pollen germination and direction of pollen elongation. It was found that all the LED light treatments had no effect on pollen germination rate but pollen avoid elongation through far-red light (Hoyo et al., 2014).

Gloxinia (Sinningia speciosa (Lodd.) Hiern), is a popular ornamental plant known for its colorful bellshaped flower that can be readily propagated using its very small seeds (approximately 28,000 seeds per gram) (Kessler, 2004). Seeds of gloxinia are sold at a relatively high price with an average of 3-5 USD per 100 seeds. Based on a greenhouse production guideline, it can take up to 6 months to grow gloxinia from seed to flowering stage (Kessler, 2004), however, there is no published information regarding suitable conditions for seed production. Use of CPPS for gloxinia seed production could provide advantages in terms of reducing cultivation time and risk of yield loss due to pests, diseases and adverse climate condition. In this study, we examined gloxinia seed production in CPPS under different LED light qualities and intensities. The aims were to gain some insights on gloxinia seed setting under LED light and explore the possibility of using CPPS for gloxinia seed production.

\section{Materials and Methods}

\section{Plant materials and growth conditions}

Seeds of gloxinia (Sinningia speciosa) F1 hybrid 'Double Brocade Blue' were obtained from Ameriseed International Co., Ltd., Chiang Mai, Thailand. The seeds were sown in a tray filled with peat moss for 14 days and then transferred to plug trays for 16 days. During this period, all seedlings were grown in CPPS at $25^{\circ} \mathrm{C}$ under white LED light (color temperature of $6500 \mathrm{~K}$ and $3200 \mathrm{~K}$ in a ratio of $1: 1)$ for $16 \mathrm{~h}$ per day under a PPFD of $150 \mu \mathrm{mol} \cdot \mathrm{m}^{-2} \cdot \mathrm{s}^{-1}$. One month after sowing, seedlings were transferred to 7 -inch plastic pots and grown under either warm white $(3200 \mathrm{~K})$, daylight $(6500 \mathrm{~K})$ (Ledonhome Trading Co., Ltd., Bangkok, Thailand) or combined red and blue (RB) LED light treatments Shigyo $^{\mathrm{TM}}$; Showa Denko K. K., Tokyo, Japan) until the end of experiment; five months after seed sowing. The spectrum details of all LED lights were published by Sakhonwasee et al. (2017). The percentages of blue $(\mathrm{B}, 400-500 \mathrm{~nm})$, green $(\mathrm{G}, 500$ $600 \mathrm{~nm}$ ), and red (R, 600-700 nm) light in each treatment, measured by Photosynthetically Active Radiation (PAR) meter (101EG; Nippon Medical \& Chemical Instruments Co., Ltd., Osaka, Japan), were 9.7\% B + $36.1 \% \mathrm{G}+54.2 \% \mathrm{R}$ for $3200 \mathrm{~K}, 26.5 \% \mathrm{~B}+39.9 \% \mathrm{G}+$ $33.6 \% \mathrm{R}$ for $6500 \mathrm{~K}$ and $30.2 \% \mathrm{~B}+2.2 \% \mathrm{G}+67.6 \% \mathrm{R}$ for RB.

Each treatment had two light intensities, 150 and $200 \mu \mathrm{mol} \cdot \mathrm{m}^{-2} \cdot \mathrm{s}^{-1}$, created by adjusting the distance between the plant canopy and light source. The photoperiod was 16 hours. The growth medium in the plug trays and the plastic pots consisted of peat moss, coarse sand, and coconut coir $(1: 1: 2, \mathrm{v} / \mathrm{v} / \mathrm{v})$. Pots were placed in a saucer $(2 \mathrm{~cm}$ high). Gloxinia plants were fertigated with modified Hoagland's solution (Epstein and Bloom, 2005) every other day until the saucer was full. When flowers were fully developed and open, they were manually self-pollinated using an eye brush.

\section{Measurement of the leaf $\mathrm{CO}_{2}$ assimilation rate}

The single-leaf $\mathrm{CO}_{2}$ assimilation rate was measured when plants were 90 and 120 days old using an LCi-SD (ADC BioScientific Ltd., Hertfordshire, UK). The youngest fully-expanded leaves of 4 individual plants were selected for measurement under either $3200 \mathrm{~K}$, $6500 \mathrm{~K}$ or RB LED light treatments at a light intensity of either 150 or $200 \mu \mathrm{mol} \cdot \mathrm{m}^{-2} \cdot \mathrm{s}^{-1}$ according to the treatments. All the measurements were carried out at the temperature of $25^{\circ} \mathrm{C}$, relative humidity of 60 $70 \%$ and ambient $\mathrm{CO}_{2}$ concentration (approximately $400 \mathrm{ppm})$.

\section{Measurements of chlorophyll fluorescence parameters}

Measurements of chlorophyll fluorescence parameters were taken when plants were 90 and 120 days old using a Fluorescence Monitoring System FMS2 
(Hansatech Instruments Ltd., King's Lynn, Norfolk, UK). All gloxinia plants had been kept in the dark for 30 minutes before the youngest fully-expanded leaves of four individual plants were selected for measurement. The maximum quantum efficiency of PSII photochemistry $\left[\mathrm{F}_{\mathrm{v}} / \mathrm{F}_{\mathrm{m}}\right.$ or $\left.\left(\mathrm{F}_{\mathrm{m}}-\mathrm{F}_{\mathrm{o}}\right) / \mathrm{F}_{\mathrm{m}}\right]$ was calculated according to Baker (2008).

\section{Analysis of pollen germination}

Pollen was collected from four individual plants from each treatment and used for pollen germination analysis based on the hanging drop method (Brewbaker and Kwack, 1963). Pollen was placed on a microscope slide, followed by droplets of liquid medium consisting of $10 \%$ sucrose, $\quad 100 \mathrm{ppm} \quad \mathrm{H}_{3} \mathrm{BO}_{3}, \quad 300 \mathrm{ppm}$ $\mathrm{Ca}\left(\mathrm{NO}_{3}\right)_{2} \cdot 4 \mathrm{H}_{2} \mathrm{O}, 200 \mathrm{ppm} \mathrm{MgSO}_{4} \cdot 7 \mathrm{H}_{2} \mathrm{O}$, and $100 \mathrm{ppm}$ $\mathrm{KNO}_{3}$. The slide was inverted and incubated inside a Petri dish containing wet paper for 30 minutes in corresponding light treatments before observation under a light microscope. Four areas of each slide were randomly selected for counting and calculating the percentage of pollen germination. Pollen tube length was analyzed one hour after incubation. Images of pollen tube growth were captured under a light microscope and tube length was calculated using ImageJ software.

\section{Image analysis of pollen and seed by scanning electron microscope}

Pollen and seed samples were collected from four individual plants in each treatment. The samples were placed on the sample stub using double side carbon tape (Agar Scientific Ltd., Essex, UK). All samples were sputter-coated with $5 \mathrm{~nm} \mathrm{Pd} / \mathrm{Au}$ using a SC 7620 sputter coater (Quorum Technologies Ltd., East Sussex, UK) before the taking of scanning electron microscope images (SEM) (EVO 25 VP; Carl Zeiss, Germany). Five images were taken from each treatment and three intact, either seeds or pollen, from each image were randomly chosen for measuring width and length using ImageJ software.

\section{Analysis of seed germination and mean germination time}

Harvested gloxinia seeds from each treatment were stored at $4^{\circ} \mathrm{C}$ for one month before analyzing seed germination and mean germination time (MGT). Accelerated aging of seeds was conducted by hanging seed packages in a container half-filled with water and then incubating at $42^{\circ} \mathrm{C}$ for three days (Rodo and Filho, 2003). The seeds were divided into four replicates (each had 50 seeds) and then placed on a wet paper towel inside a Petri dish. Seeds were germinated under LED light $3200 \mathrm{~K}$ and $6500 \mathrm{~K}(1: 1)$ at light intensity of $150 \mu \mathrm{mol} \cdot \mathrm{m}^{-2} \cdot \mathrm{s}^{-1}$ for 14 days. Germinated seeds were counted every day to calculate MGT and percentage of seed germination. MGT was calculated following Mavi et al. (2010):

$$
\mathrm{MGT}=\Sigma(\mathrm{nT}) / \Sigma_{\mathrm{n}}
$$

where $\mathrm{n}=$ number of germinated seeds at day $\mathrm{T}$ and $\Sigma_{\mathrm{n}}$ $=$ number of germinated seeds on final day.

Other measurements, experimental design, and statistical analysis

Shoot and root dry weight (obtained after samples were incubated at $95^{\circ} \mathrm{C}$ for three days), canopy width and the length of petioles were recorded after 60 days of light treatment. Manual pollination ceased when gloxinia plants were four months old. Cumulative seed yield data were collected until the plants were five months old. A completely randomized design was used for the experiment. One-, two-, and three-way ANOVA tests $(P<0.05)$ were performed using SPSS 22.0 (IBM Corporation, Armonk, NY, USA). Data are reported as mean \pm standard error (SE). Significant differences among means were determined by Tukey's post hoc test $(P<0.05)$ in SPSS 22.0.

\section{Results}

\section{Growth and development of gloxinia plants}

After exposure to different light treatments for 60 days, gloxinia plants grown under $3200 \mathrm{~K}$ light at $200 \mu \mathrm{mol} \cdot \mathrm{m}^{-2} \cdot \mathrm{s}^{-1}$ exhibited the highest average shoot dry weights, whereas those in the other five treatments had no significant differences (Fig. 1a). There was no significant difference in root dry weights between treatments (Fig. 1b). Light quality significantly affected length of petiole, and plants grown under RB light exhibited the narrowest canopy width, shortest length of petiole (Fig. 1c, d) and most compact canopy (Fig. 2).

\section{Photosynthesis of gloxinia plants}

Leaf $\mathrm{CO}_{2}$ assimilation rate and $\mathrm{F}_{\mathrm{v}} / \mathrm{F}_{\mathrm{m}}$ values were measured twice at 90 and 120 days after sowing. The $\mathrm{CO}_{2}$ assimilation rate was found to be highest in plants grown under RB light at $200 \mu \mathrm{mol} \cdot \mathrm{m}^{-2} \cdot \mathrm{s}^{-1}$ at both time points, whereas $F_{v} / F_{m}$ values were not significantly different among all light treatments at the same time point (Fig. 3a, b). The age of the plants significantly affects $\mathrm{CO}_{2}$ assimilation rate, with the values obtained from the measurement at 90 days higher than those at 120 days.

\section{Reproductive development of gloxinia plants}

Flowering of gloxinia plants occurred at a similar period in all treatments (Fig. 4a). Light intensity significantly affected number of flowers, where plants grown in the light intensity of $200 \mu \mathrm{mol} \cdot \mathrm{m}^{-2} \cdot \mathrm{s}^{-1}$ had fewer flowers than those grown under $150 \mu \mathrm{mol} \cdot \mathrm{m}^{-2} \cdot \mathrm{s}^{-1}$ (Fig. 4b). There was no significant difference in flower diameter among treatments (Fig. 4c). Notably, plants grown under $\mathrm{RB}$ light at $150 \mu \mathrm{mol} \cdot \mathrm{m}^{-2} \cdot \mathrm{s}^{-1}$ had the highest percentage of pod set although this is not statistically significant (Fig. 4d). After five months of cultivation, the plants grown under RB light at 

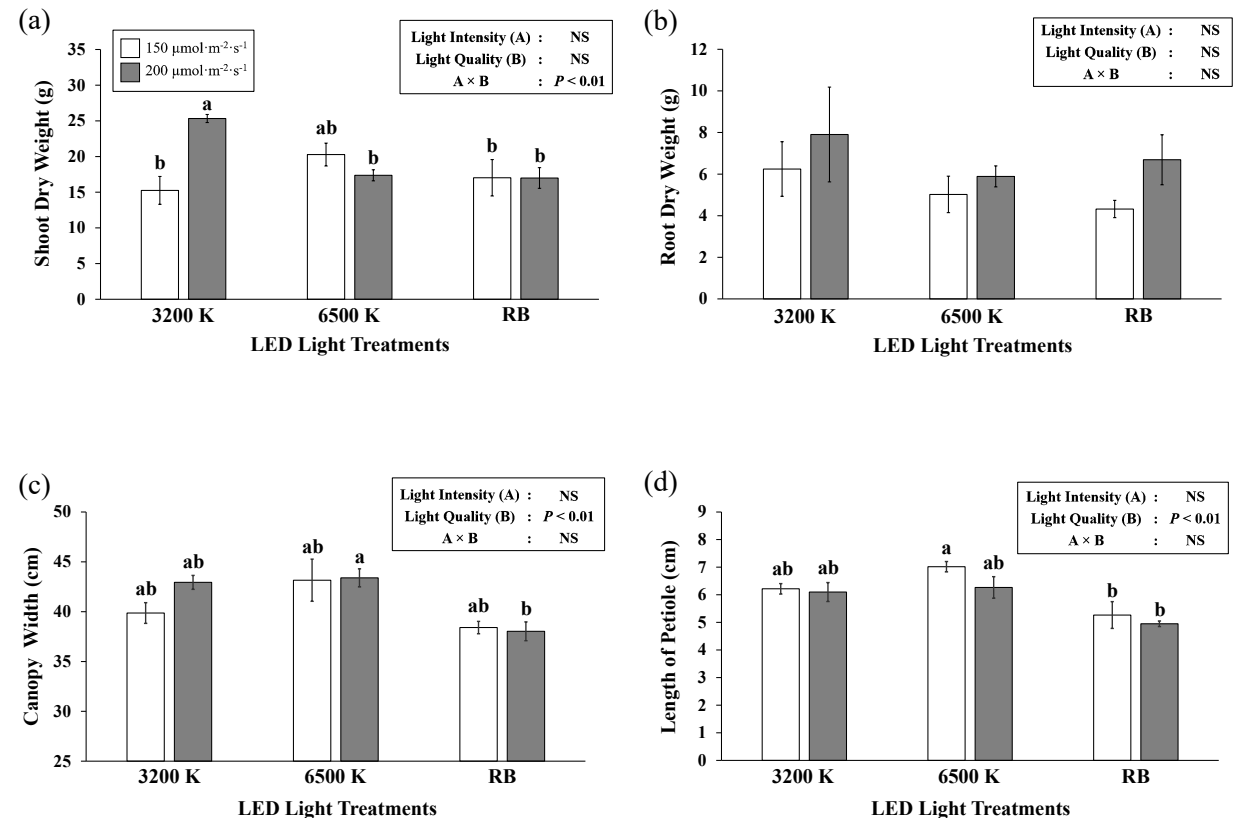

Fig. 1. Influence of different LED light treatments on vegetative growth of gloxinia plants. Data were collected after gloxinia plants were grown under each light treatment for 60 days. (a) shoot dry weight (b) root dry weight (c) canopy width (d) length of petiole. Values are means $\pm \mathrm{SE}$ $(\mathrm{n}=4-6)$. Different letters indicate significant differences $(P<0.05)$ between LED light treatments. Significant differences were determined using Tukey's test.

150 $\mu \mathrm{mol} \cdot \mathbf{m}^{-2} \cdot \sec ^{-1}$

200 $\mu \mathrm{mol} \cdot \mathrm{m}^{-2} \cdot \mathrm{sec}^{-1}$
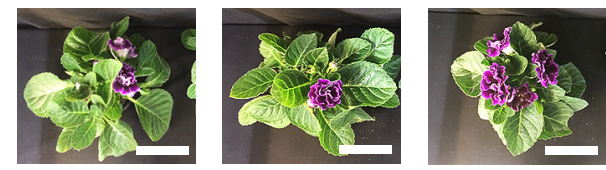

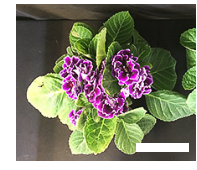

$3200 \mathrm{~K}$

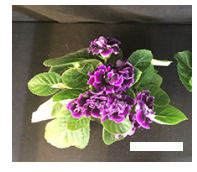

$6500 \mathrm{~K}$

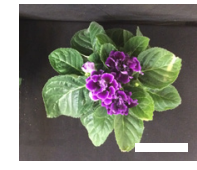

RB
Fig. 2. Top view of gloxinia plants after being grown under different LED light treatments at 90 days after sowing. White bar $=15.24 \mathrm{~cm}$.

$150 \mu \mathrm{mol} \cdot \mathrm{m}^{-2} \cdot \mathrm{s}^{-1}$ produced the highest total weight of seed per plant, followed by those grown under $3200 \mathrm{~K}$ light at $150 \mu \mathrm{mol} \cdot \mathrm{m}^{-2} \cdot \mathrm{s}^{-1}$ (Fig. 4e). Seeds derived from gloxinia plants grown under RB light were heavier than those from the other light quality treatments (Fig. 4f).

\section{Pollen morphology and germination}

Pollen length was significantly influenced by age and light quality (Fig. 5a). Gloxinia plants grown under RB light had the longest pollen when compared at the same age and light intensity. Pollen from plants grown under $6500 \mathrm{~K}$ light at $200 \mu \mathrm{mol} \cdot \mathrm{m}^{-2} \cdot \mathrm{s}^{-1}$ for 130 days (Fig. 5b) was the widest and its distinctive shape can be clearly seen through SEM imagery (Fig. 5c).

Percentage of pollen germination was not significantly different among treatments (Fig. 6a). However, after incubation in liquid medium for one hour, the pollen
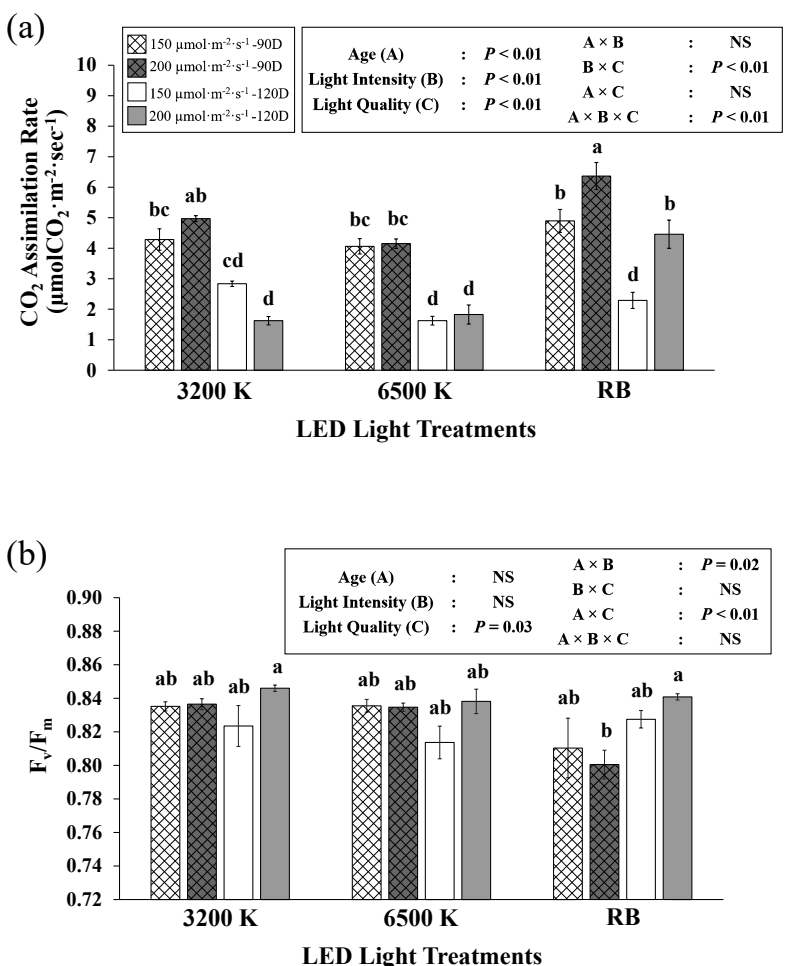

Fig. 3. Influence of different LED light treatments on (a) $\mathrm{CO}_{2}$ assimilation rate and (b) $F_{v} / F_{m}$ or maximum quantum efficiency of PSII in a dark-adapted state of gloxinia plants at 90 and 120 days after sowing. Values are means $\pm \mathrm{SE}(\mathrm{n}=6)$. Different letters indicate significant differences $(P<0.05)$ between LED light treatments. Significant differences were determined using Tukey's test. 
(a)

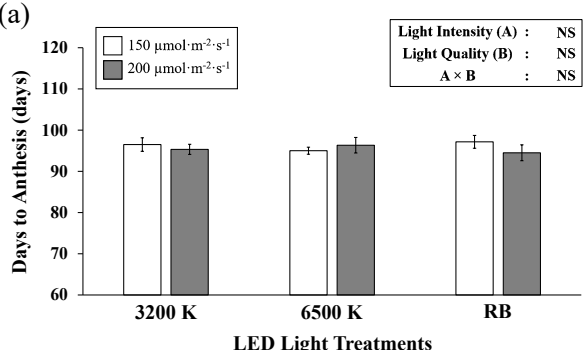

(c)

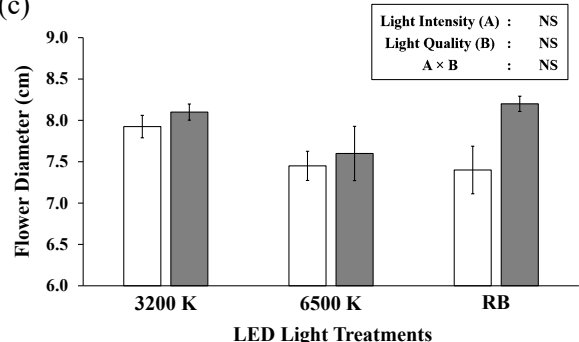

(e)

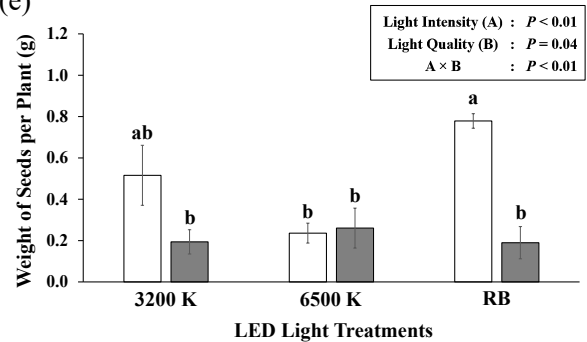

(b)

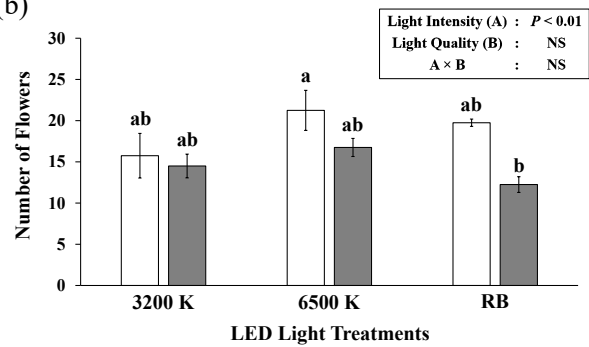

(d)

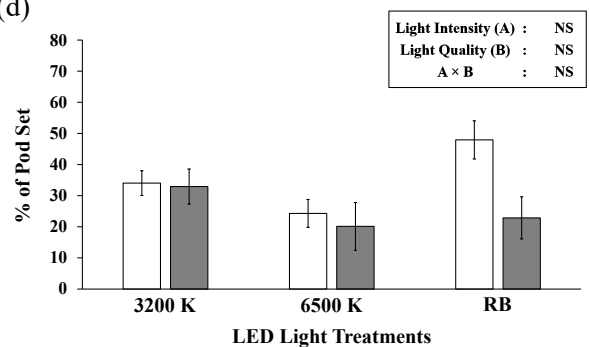

(f)

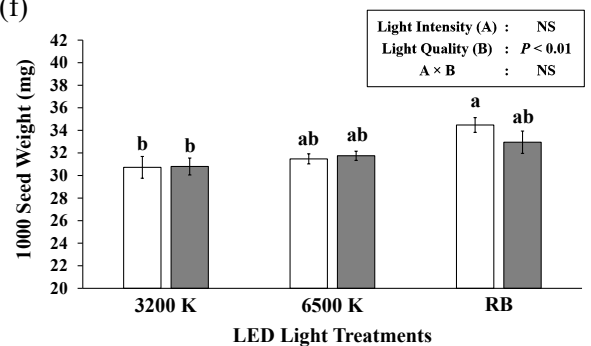

Fig. 4. Influence of different LED light treatments on reproductive development of gloxinia plants. Cumulative data were collected over 5 months. (a) days to anthesis (b) number of flowers (c) flower diameters (d) percentage of pod set (e) weight of seeds per plant (f) 1,000 seed weight. Values are means $\pm \mathrm{SE}(\mathrm{n}=6)$. Different letters indicate significant differences $(P<0.05)$ between LED light treatments. Differences between treatments were determined using Tukey's test.

tubes of plants grown under RB light were longer than the other treatments (Fig. 6b).

\section{Seed morphology and germination}

Seeds obtained from gloxinia plants grown under RB light were longest when compared to the other light quality treatments (Fig. 7a). The effect of light quality on seed length and width significantly depended on light intensity (Fig. 7a, b). Germination percentage of seeds from all light treatments was higher than $80 \%$ and there was no significant difference between treatments (Fig. 8a). Accelerated aging of gloxinia seeds resulted in an overall reduction of germination, but there was no significant difference among the treatments (Fig. 8b). MGT of both normal and accelerated aging gloxinia seeds was not significantly different between treatments (Fig. 8c, d).

\section{Discussion}

Using gloxinia as a model, we have shown that quality seeds, with high germination percentage and seed vigor, may be successfully produced in CPPS, and that artificial light conditions influence some aspects of plant development and seed production. The results suggest that some light conditions may promote vegetative growth (Fig. 1a, b) without any significant effect on seed yield and quality (Figs. 4e and 8a-d). This is not favorable because promoting vegetative growth increases space requirements inside CPPS and is only viable when seed yield or quality is also improved. In contrast, treatment by RB light resulted in plants with compacted canopy without compromising seed yield, which is preferable for seed production. (Figs. 1c, d, 2, and 4e). A previous study on Jatropha curcas, showed that inhibiting vegetative growth using a plant growth retardant may result in higher seed yield due to a shift in nutrient allocation to reproductive organs (Ghosh et al., 2010). This may provide an option to increase seed yield per unit area while minimizing cultivation space in CPPS.

Results from this study showed that gloxinia plants grown under $\mathrm{RB}$ light at the intensity of $150 \mu \mathrm{mol} \cdot \mathrm{m}^{-2} \cdot \mathrm{s}^{-1}$ produced much higher seed yield than those grown under $200 \mu \mathrm{mol} \cdot \mathrm{m}^{-2} \cdot \mathrm{s}^{-1}$ and the other 

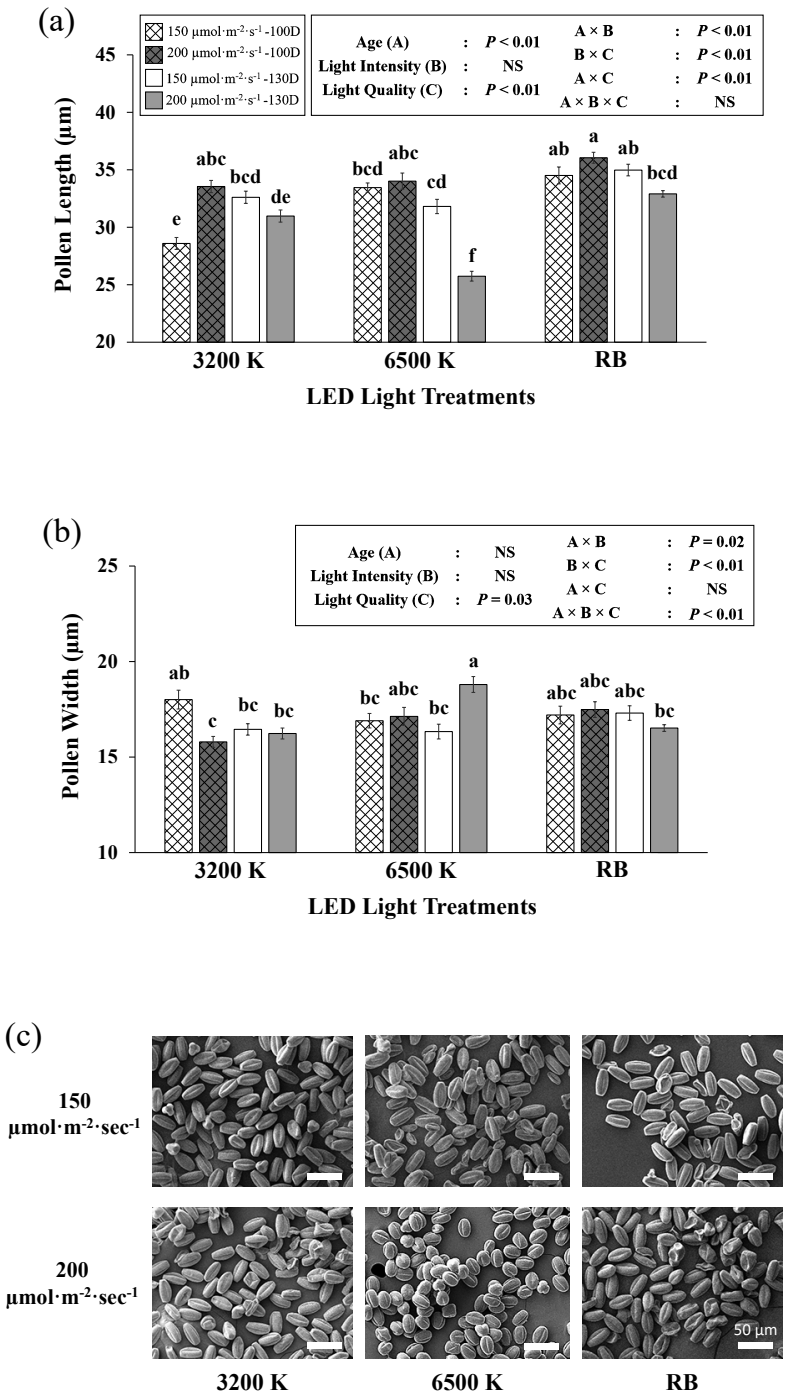

Fig. 5. Influence of different LED light treatments on pollen morphology of gloxinia plants. (a) pollen length (b) pollen width (c) SEM image of pollen at 130 days after sowing. Values are means $\pm \mathrm{SE}(\mathrm{n}=15)$. Different letters indicate significant differences $(P<0.05)$ between LED light treatments. Significant differences were determined using Tukey's test. White $\mathrm{bar}=50 \mu \mathrm{m}$.

light treatments (Fig. 4e). The lower seed yield in the RB light at $200 \mu \mathrm{mol} \cdot \mathrm{m}^{-2} \cdot \mathrm{s}^{-1}$ treatment cannot be attributed to light stress since the vegetative growth of the plants in the treatment was similar to those grown at $150 \mu \mathrm{mol} \cdot \mathrm{m}^{-2} \cdot \mathrm{s}^{-1}$ (Fig. 1a). $\mathrm{F}_{\mathrm{v}} / \mathrm{F}_{\mathrm{m}}$ values from all treatments were about 0.8 and not statistically significant throughout the experiment (Fig. 3b), indicating that all the plants had a similar level of PSII capacity (Maxwell and Johnson, 2000). Single leaf $\mathrm{CO}_{2}$ assimilation rate was found to be highest in the RB light at $200 \mu \mathrm{mol} \cdot \mathrm{m}^{-2} \cdot \mathrm{s}^{-1}$ treatment (Fig. 3a). Thus, high seed yield in the plants grown under RB light at $150 \mu \mathrm{mol} \cdot \mathrm{m}^{-2} \cdot \mathrm{s}^{-1}$ may not be occurring due to better photosynthetic performance.

To further investigate the cause of the difference in
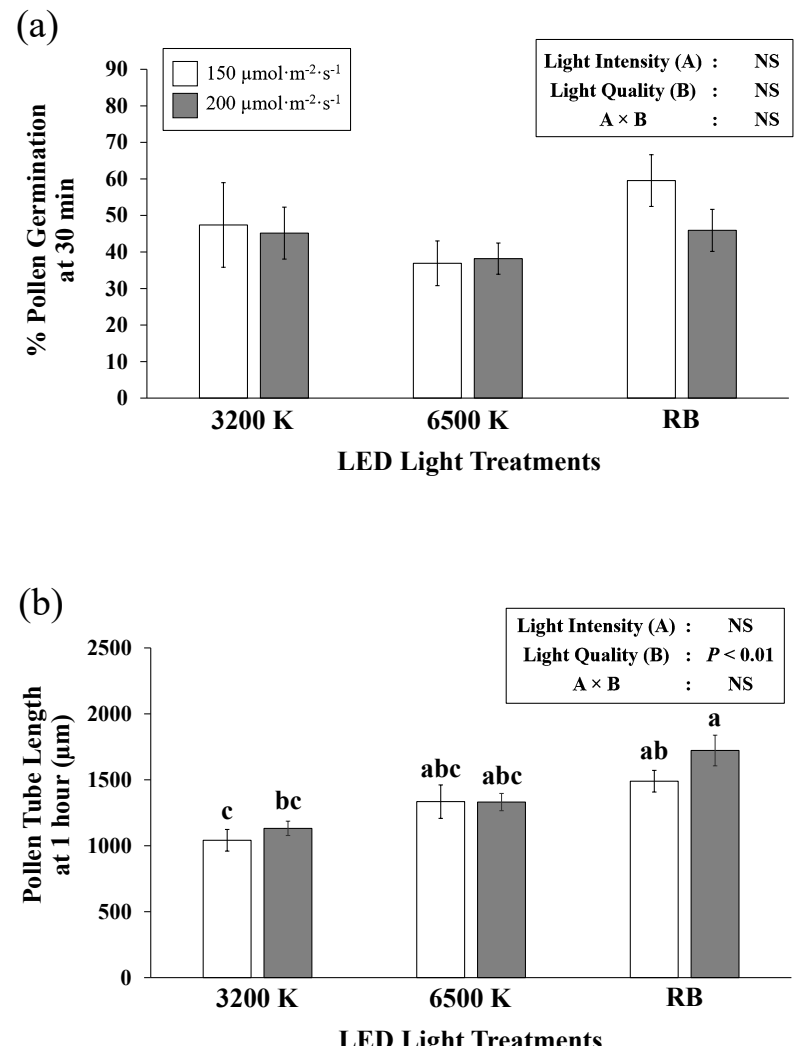

Fig. 6. Influence of different LED light treatments on (a) pollen germination (b) pollen tube elongation at 130 days after sowing. Values are means $\pm S E(n=6$ for pollen germination and $\mathrm{n}=20$ for pollen tube length). Different letters indicate significant differences $(P<0.05)$ between LED light treatments. Significant differences were determined using Tukey's test.

seed yield, pollen germination was examined. While the percentage of pollen germination was similar in all treatments, pollen tube elongation was significantly higher in plants grown under RB light (Fig. 6a, b). Previous reports showed that red light promoted pollen tube elongation (Chhabra and Malik, 1978; Dhawan and Malik, 1981). Accordingly, the RB light had the highest proportion of red light. Pollen grains from gloxinia grown under RB light were also longer than those from the other light treatments (Fig. 5a). It was reported that pollen from high nitrogen treated plants is larger than from low nitrogen treated plants (Lau and Stephenson, 1993). Larger pollen size may, therefore, imply more storage of nutrient compounds, such as phytic acid, proteins and carbohydrates, which support pollen germination and elongation (Johri and Vasil, 1961; Jackson and Linskens, 1982). Based on data from this study, it is still unclear how RB light treatment led to an increase of pollen size, but this may be a desirable trait for seed production inside CPPS.

Gloxinia plants grown in light at $200 \mu \mathrm{mol} \cdot \mathrm{m}^{-2} \cdot \mathrm{s}^{-1}$ were found to have a lower flower number than those grown under $150 \mu \mathrm{mol} \cdot \mathrm{m}^{-2} \cdot \mathrm{s}^{-1}$ (Fig. 4b). These results differ from previous studies in other plant species, 


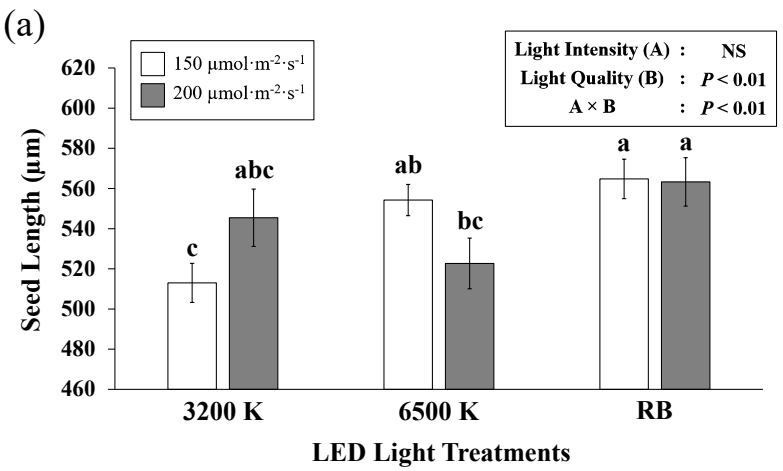

(b)

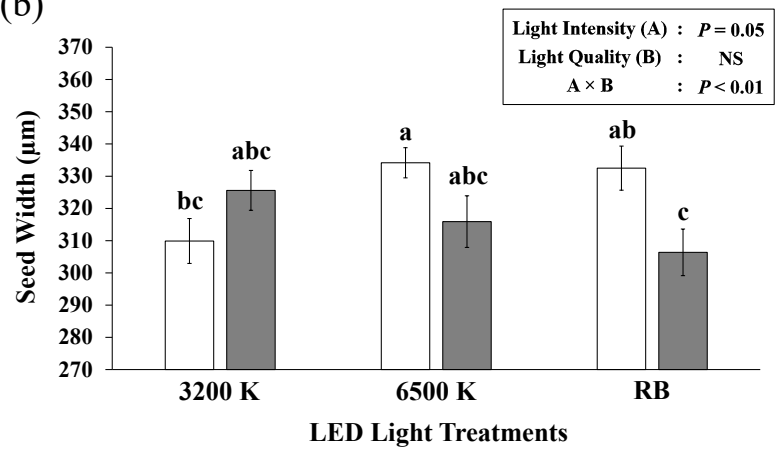

Fig. 7. Influence of different LED light treatments on gloxinia seed morphology. (a) seed length (b) seed width. Values are means $\pm \mathrm{SE}(\mathrm{n}=40)$. Different letters indicate significant differences $(P<0.05)$ between LED light treatments. Significant differences were determined using Tukey's test. where increasing light intensity promotes flower formation (Tsukamoto et al., 1971; Munir et al., 2004). It is conceivable that the effect of light intensity on flower development may depend on plant species and it is necessary to optimize light intensity inside CPPS for individual species to maximize seed yield. Hence, high seed yield in gloxinia plants grown under RB light at $150 \mu \mathrm{mol} \cdot \mathrm{m}^{-2} \cdot \mathrm{s}^{-1}$ may be a result of both superior pollen tube elongation and higher flower number. Day to anthesis, flower diameter and percentage of pod set of gloxinias in all light treatments were not significantly different and therefore cannot be used to explain the difference in seed yield among treatments (Fig. 4a, c, d).

Another effect of light condition on pollen was found in plants grown under $6500 \mathrm{~K}$ light at $200 \mu \mathrm{mol} \cdot \mathrm{m}^{-2} \cdot \mathrm{s}^{-1}$ where pollen is much shorter and wider than the other treatments after 130 days of cultivation (Fig. 5a-c). Reduced pollen size during the course of cultivation has been suggested to be an indirect consequence of flower, fruit and seed developments which draw nutrient resources from pollen (Lau et al., 1995). Results from this study provide no evidence to support this hypothesis as gloxinia plants grown under $6500 \mathrm{~K}$ light at $200 \mu \mathrm{mol} \cdot \mathrm{m}^{-2} \cdot \mathrm{s}^{-1}$ produced similar size and amounts of flowers and less seeds than plants from treatment of RB light at $150 \mu \mathrm{mol} \cdot \mathrm{m}^{-2} \cdot \mathrm{s}^{-1}$ (Fig. 4b, c, e). The shortening effect of $6500 \mathrm{~K}$ light on pollen here is reminiscent of a previous report in soybean where application of cool white LED light (color temperature of 6000-7000 K) resulted in shorter stems than those grown under warm white LED light (color temperature of 2800-3200 K) without any effect on dry weight (Cope and Bugbee,
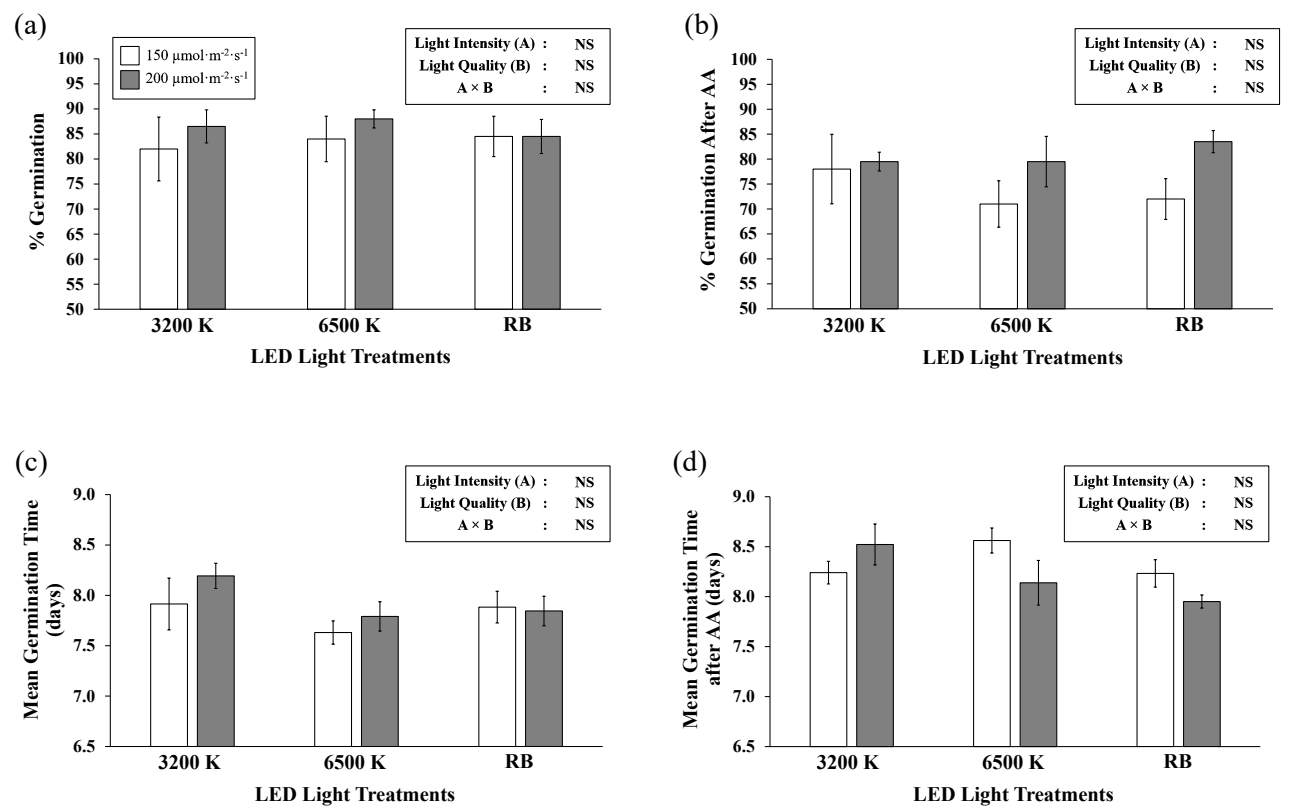

Fig. 8. Influence of different LED light treatments on gloxinia seed vigor. (a) percentage of seed germination (b) percentage of seed germination after accelerated aging (AA) (c) mean germination time (d) mean germination time after AA. Values are means \pm SE $(n=4)$. Different letters indicate significant differences $(P<0.05)$ between LED light treatments. Significant differences were determined using Tukey's test. 
2013). Therefore, reduction of pollen size in this case could be attributable to the direct effect of light treatment on pollen development.

Similar to the case of pollen, RB light treatment results in heavier and longer gloxinia seeds than the other light treatments (Figs. $4 \mathrm{f}$ and $7 \mathrm{a}$ ). Upadhaya et al. (2007) suggested larger seed size could mean more nutrient storage in the seed to support germination and higher seed vigor. However, there was no significant difference here in percentage of germination and MGT between seeds from all light treatments, even after an accelerated aging process (Fig. 8a-d). It is possible that a difference in seed quality between the treatments may arise after the application of more severe stress conditions.

\section{Conclusion}

In conclusion, results from this study demonstrate the potential of CPPS for seed production. RB light was found to be superior to white light for gloxinia seed production as it produced plants with compact canopies and larger pollen size, which correlated with greater pollen tube elongation. The fact that gloxinia plants grown under RB light at $150 \mu \mathrm{mol} \cdot \mathrm{m}^{-2} \cdot \mathrm{s}^{-1}$ exhibited higher seed yield than those grown under the same light quality but with a higher light intensity implies that the effect of light quality on seed production in CPPS is dependent on light intensity. The quality of seeds derived from CPPS is commercially acceptable as indicated by the percentage of seed germination from all treatments, which was higher than $80 \%$. Results from this experiment showed that about 0.77 grams of gloxinia seed (approximately 22,000 seeds) (Fig. 4e) can be produced from 1 gloxinia plant grown for 5 months in CPPS.

\section{Acknowledgements}

This work was funded by the Faculty of Agricultural Production, Maejo University, Chiang Mai. We wish to thank Mr. Clive Richardson and Ameriseed International Co., Ltd. for providing seeds and important information about growing gloxinia throughout the experiment. We thank the Institute of Product Quality and Standardization (IQS) of Maejo University for providing access to the photosynthesis system and other laboratory equipment. We thank Mr. Hironori Ara from Showa Denko K.K. for kindly providing red-blue LED tubes for this experiment. We thank Dr. Chaiwat Prawettongsopon and Carl Zeiss Co., Ltd., Thailand for SEM analysis of gloxinia pollens and seeds. Finally, we thank Drs. Preeda Nathewet and Ian Bennett for reviewing our manuscript.

\section{Literature Cited}

Baker, N. R. 2008. Chlorophyll fluorescence: a probe of photosynthesis in vivo. Annu. Rev. Plant. Biol. 59: 89-113.

Brewbaker, J. L. and B. H. Kwack. 1963. The essential role of calcium ion in pollen germination and pollen tube growth. Am. J. Bot. 50: 859-865.

Campbell, A. W., W. B. Griffin, D. J. Burritt and A. J. Conner. 2001. The importance of light intensity for pollen tube growth and embryo survival in wheat $\times$ maize crosses. Ann. Bot. 87: 517-522

Chhabra, N. and C. P. Malik. 1978. Influence of spectral quality of light on pollen tube elongation in Arachis hypogaea. Ann. Bot. 42: 1109-1117.

Cope, K. R. and B. Bugbee. 2013. Spectral effects of three types of white light-emitting diodes on plant growth and development: absolute versus relative amounts of blue light. HortScience 48: 504-509.

Dhawan, A. K. and C. P. Malik. 1981. Effect of growth regulators and light on pollen germination and pollen tube growth in Pinus roxburghii Sarg. Ann. Bot. 47: 239-248.

Epstein, E. and A. J. Bloom. 2005. Mineral nutrition of plants: principles and perspectives. Second edition. Sinauer Associates.

FAO. 2018. Seeds toolkit-Module 5: Seed marketing. Rome.

Fukuda, N., C. Ajima, T. Yukawa and J. E. Olsen. 2016. Antagonistic action of blue and red light on shoot elongation in petunia depends on gibberellin, but the effects on flowering are not generally linked to gibberellin. Environ. Exp. Bot. 121: $102-111$.

Ghosh, A., J. Chikara, D. R. Chaudhary, A. R. Prakash, G. Boricha and A. Zala. 2010. Paclobutrazol arrests vegetative growth and unveils unexpressed yield potential of Jatropha curcas. J. Plant Growth Regul. 29: 307-315.

Hampton, J. G., B. Boelt, M. P. Rolston and T. G. Chastain. 2013. Effects of elevated $\mathrm{CO}_{2}$ and temperature on seed quality. J. Agric. Sci. 151: 154-162.

Hampton, J. G., A. J. Conner, B. Boelt, T. G. Chastain and P. Rolston. 2016. Climate change: seed production and options for adaptation. Agriculture 6: 33. DOI: 10.3390/agriculture 6030033.

Heo, J. W., C. W. Lee, H. N. Murthy and K. Y. Paek. 2003. Influence of light quality and photoperiod on flowering of Cyclamen persicum Mill. cv. 'Dixie White'. Plant Growth Regul. 40: 7-10.

Hoyo, Y., K. Fujiwara and Y. Hoshino. 2014. Effects of different wavelengths of LED light on pollen germination and direction of pollen tube elongation in Cyrtanthus mackenii. Adv. Hort. Sci. 28: 190-194.

IHS Markit Agribusiness Consulting. 2019. Analysis of sales and profitability within the seed sector. Independent report prepared for the co-chairs of the ad-hoc open-ended working group to enhance the functioning of the Multilateral System of Access and Benefit-sharing of FAO's International Treaty on Plant Genetic Resources for Food and Agriculture.

Jackson, J. F. and H. F. Linskens. 1982. Phytic acid in Petunia hybrida pollen is hydrolyzed during germination by a phytase. Acta Bot. Neerl. 31: 441-447.

Jähne, F., V. Hahn, T. Würschum and W. L. Leiser. 2020. Speed breeding short-day crops by LED-controlled light schemes. Theor. Appl. Genet. 133: 2335-2342.

Johri, B. M. and I. K. Vasil. 1961. Physiology of pollen. Bot. Rev. 27: $325-381$.

Kessler, J. R. 2004. Greenhouse production of gloxinias. Alabama Cooperative Extension System. 2.1M, New Sept, ANR-1258

Kozai, T. and G. Niu. 2016. Chapter 27: Challenges for the nextgeneration PFAL. p. 387-393. In: T. Kozai, G. Niu and M. Takagaki (eds.). Plant Factory: An indoor vertical farming system for efficient quality food production. Academic 
Press. Cambridge, MA.

Lau, T. C. and A. G. Stephenson. 1993. Effects of soil nitrogen on pollen production, pollen grain size, and pollen performance in Cucurbita pepo (Cucurbitaceae). Am. J. Bot. 80: 763768.

Lau, T. C., R. T. Koide and A. G. Stephenson. 1995. Effects of soil fertility and mycorrhizal infection on pollen production and pollen grain size of Cucurbita pepo (Cucurbitaceae). Plant Cell Env. 18: 169-177.

Mavi, K., I. Demir and S. Matthews. 2010. Mean germination time estimates the relative emergence of seed lots of three cucurbit crops under stress conditions. Seed Sci. \& Technol. 38: $14-25$.

Maxwell, K. and G. N. Johnson. 2000. Chlorophyll fluorescence -a practical guide. J. Exp. Bot. 51: 659-668.

McDonald, M. B. and F. Y. Kwong. 2005. Chapter 1: Introduction to flower seeds and the flower seed industry. p. 1-5. In: M. B. McDonald and F. Y. Kwong (eds.). Flower seeds biology and technology. CABI Publishing.

Munir, M., M. Jamil, J. Baloch and K. R. Khattak. 2004. Impact of light intensity on flowering time and plant quality of Antirrhinum majus L. cultivar Chimes White. J. Zhejiang Univ. Sci. 5: 400-405.
Niam, A. G., T. R. Muharam, S. Widodo, M. Solahudin and L. Sucahyo. 2019. CFD simulation approach in determining air conditioners position in the mini plant factory for shallot seed production. AIP Conference Proceedings 2062: 020017. DOI: $10.1063 / 1.5086564$.

Park, I. S., K. J. Cho, J. Kim, J. Y. Cho, T. J. Lim and W. Oh. 2016. Growth and flowering responses of Petunia to various artificial light sources with different light qualities. Korean J. Hortic. Sci. Technol. 34: 55-66.

Rodo, A. B. and J. M. Filho. 2003. Accelerated aging and controlled deterioration for the determination of the physiological potential of onion seeds. Sci. Agri. 60: 465-469.

Sakhonwasee, S., K. Thummachai and N. Nimnoy. 2017. Influences of LED light quality and intensity on stomatal behavior of three petunia cultivars grown in a semi-closed system. Environ. Control. Biol. 55: 93-103.

Tsukamoto, Y., H. Imanishi and H. Yahara. 1971. Studies on the flowering of marigold. II. Interactions among day-length, temperature, light intensity and plant regulators. J. Japan. Soc. Hort. Sci. 40: 65-70.

Upadhaya, K., H. N. Pandey and P. S. Law. 2007. The effect of seed mass on germination, seedling survival and growth in Prunus jenkinsii Hook. f. \& Thoms. Turk. J. Bot. 31: 31-36. 